\title{
Controlled Synthesis of Isotactic and Symmetrical Poly(methyl methacrylate) Directed toward Uniform Polymers with High Crystallinity
}

\author{
Koichi Ute, Yumi Yamasaki, Masami Naito, Nobuo Miyatake, and Koichi Hatada* \\ Department of Chemistry, Faculty of Engineering Science, Osaka University, \\ Toyonaka, Osaka 560, Japan
}

(Received May 1, 1995)

\begin{abstract}
The synthesis and fractionation by supercritical fluid chromatography (SFC) of an isotactic and symmetrical poly(methyl methacrylate) (PMMA) containing very few configurational defects, $\mathrm{H}-(\mathrm{MMA})_{n} \mathrm{CH}_{3}$ (2), are described. Detailed analysis by ${ }^{1} \mathrm{H}$ NMR spectroscopy showed that the PMMA 2 was almost perfectly isotactic $(\sim 100 \%)$ except a small amount $(11 \%)$ of racemo sequence at the first tactic diad from the initiating chain-end. The uniform PMMAs 2 with $31,36,41$, and 44 repeating units (n) had melting points higher by $4.5-12.2^{\circ} \mathrm{C}$ than those of the uniform PMMAs prepared in a previous work, $t-\mathrm{C}_{4} \mathrm{H}_{9}(-\mathrm{MMA})_{n} \mathrm{H}(\mathbf{1})$ with a triad isotacticity of $96.1 \%$. The degrees of crystallinity of the uniform PMMA 2 samples were determined to be $92-97 \%$, also high as compared with those of uniform PMMA 1 samples. Single crystals were grown from a solution of the 7 mer of $\mathbf{2}(n=7)$, and the crystal structure was determined by X-ray analysis.

KEY WORDS Uniform Polymer / Supercritical Fluid Chromatography / Living Polymerization / Tacticity / End-Group / Melting Temperature / Degree of Crystallinity / X-Ray Crystallographic Analysis /
\end{abstract}

Polymerization of methyl methacrylate (MMA) initiated with $t-\mathrm{C}_{4} \mathrm{H}_{9} \mathrm{MgBr}$ in toluene at $-78^{\circ} \mathrm{C}$ proceeds in a living manner to yield a highly isotactic PMMA with a well-defined chain structure (1). ${ }^{1}$

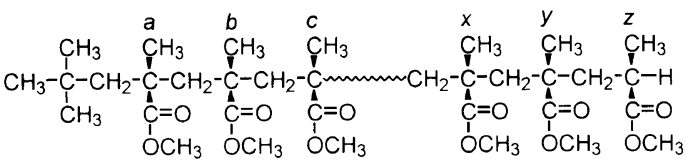

[1]

Recently, we have succeeded in fractionating this PMMA into the individual homologues from 3mer $\left(\mathrm{C}_{19} \mathrm{H}_{34} \mathrm{O}_{6}=358.5\right)$ to $100 \mathrm{mer}$ $\left(\mathrm{C}_{504} \mathrm{H}_{810} \mathrm{O}_{200}=10069.9\right)$ by means of supercritical fluid chromatography (SFC). ${ }^{2-6} \mathrm{~A}$ series of the uniform isotactic PMMAs was subjected to investigations of its glass transition temperature $\left(T_{\mathrm{g}}\right),{ }^{3,5,7}$ crystalline melting tem- perature $\left(T_{\mathrm{m}}\right),{ }^{5,7}$ and of the stereocomplexation with uniform syndiotactic PMMAs. ${ }^{3,4}$ Usefulness of the uniform PMMAs as a standard material for molecular weight determinations has also been demonstrated. ${ }^{4,5}$ Although the purity of the uniform PMMAs with respect to degree of polymerization $(D P)$ was proved to be higher than $99 \%$ by $\mathrm{SFC}^{3,4}$ and mass spectrometry, ${ }^{8}$ there still remains a purity problem at the stereochemical level. The isotacticity of the parent PMMA 1 is $96-97 \%$ in triads, and thus the isolated $50 \mathrm{mer}$, for example, should contain statistically one racemo $(r)$ diad somewhere in its configurational sequence. Moreover, the uniform PMMAs have configurational disorder at the chain-end diads (the $a-b$ and $y-z$ diads in eq $\mathbf{1}$ ) because the stereospecificity in the initiation ${ }^{9}$ and termination processes ${ }^{10}$ of the polymerization was found to be 90 and $94 \%$ in meso $(\mathrm{m})$ 
diad, respectively.

In the present paper, we report the synthesis and SFC fractionation of an isotactic and symmetrical PMMA (2) containing very few $r$ diads throughout the whole polymer chain.

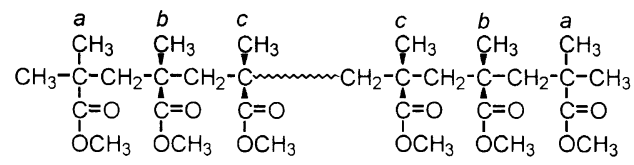

[2]

This synthesis takes advantage of the high stereospecificity in the living polymerization of triphenylmethyl methacrylate (TrMA) ${ }^{1-13}$ or 1-phenyldibenzosuberyl methacrylate (PDBSMA) ${ }^{14}$ at low temperatures; these bulky methacrylates polymerize to give almost perfectly isotactic polymers with rigid helical structure due to the steric interactions of the ester groups. The stereoisomerism in the termination process can be avoided by introducing a methyl end-group to the polymer anions. The resulting polymer is readily convertible into PMMA by hydrolytic cleavage of the ester functions and subsequent methylation with diazomethane. The synthetic procedure is illustrated in Scheme 1 using PDBSMA as a starting monomer.

An added rationale for this study is that the simple and symmetrical chain-structure of $\mathbf{2}$ is expected to facilitate crystallization and would minimize the end-group effects on conformational structure and physical properties. Volpe and Hogen-Esch have prepared the atactic and

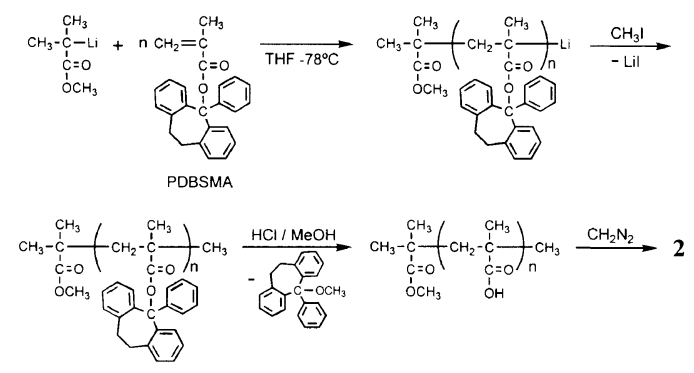

Scheme 1. syndiotactic-rich oligo(MMA)s of structure 2 by the polymerization of MMA with enolates of methyl isobutyrate and determined isomeric ratios for the oligomers from 2 mer to $6 \mathrm{mer}$ obtained by chromatographic separation ${ }^{15}$; the simplicity of their ${ }^{1} \mathrm{H}$ and ${ }^{13} \mathrm{C}$ NMR spectra was essential for the unambiguous assignment of the stereoisomers. This is also the case for our uniform isotactic PMMA 2.

\section{EXPERIMENTAL}

\section{Materials}

TrMA (mp 102.5-102.8 ${ }^{\circ}$ ) and PDBSMA (mp $154.2-155.2^{\circ} \mathrm{C}$ ) were prepared by the procedure described in the literature. ${ }^{14,16}$ Nakano and his coworkers have reported the mp of PDBSMA to be $117^{\circ} \mathrm{C} .{ }^{14}$ The reason for the discrepancy in $\mathrm{mp}$ is not clear at present. Methyl and $t$-butyl $\alpha$-lithioisobutyrates were prepared according to the method reported by Lochmann et al. ${ }^{17} \mathrm{THF}$ and methyl iodide were dried over $\mathrm{LiAlH}_{4}$ and $\mathrm{CaH}_{2}$, respectively, and vacuum distilled just before use.

\section{Preparation of PMMA 2}

Several samples of parent PMMA 2 differing in $\bar{M}_{n}$ were synthesized. A representative procedure is as follows ( $c f$., Scheme 1). Polymerization of PDBSMA $(16.9 \mathrm{mmol})$ in THF $(65 \mathrm{ml})$ at $-78^{\circ} \mathrm{C}$ was initiated with methyl $\alpha$-lithioisobutyrate $(0.48 \mathrm{mmol})$ under dry nitrogen atmosphere. After $4 \mathrm{~h}$, methyl iodide $(4.8 \mathrm{mmol})$ was introduced to the polymerization mixture with stirring and allowed to react for $16 \mathrm{~h}$ at $-78^{\circ} \mathrm{C}$, for additional $48 \mathrm{~h}$ at $-40^{\circ} \mathrm{C}$, and then for $1 \mathrm{~h}$ at $0^{\circ} \mathrm{C}$. Finally, a small amount of methanol was added. The mixture was concentrated to about $40 \mathrm{ml}$ in volume, and then poured into $800 \mathrm{ml}$ of methanol. The insoluble part (yield $97.3 \%$ ) was collected by centrifugation, washed several times with methanol, and dried in vacuo at $40^{\circ} \mathrm{C}$ for $3 \mathrm{~h}$. The poly(PDBSMA) was converted into poly(methacrylic acid) by refluxing 
in $2 \% \mathrm{HCl} /$ methanol for $26 \mathrm{~h}$. On cooling, 10,11-dihydro-5-methoxy-5-phenyl-5 $H$-dibenzo[a,d]cycloheptene (1-methoxy-1-phenyldibenzosuberane) was crystallized out from the solution and removed by filtration. The poly(methacrylic acid) was recovered by evaporating the solvent, washed several times with ether, and dried in vacuo for $1 \mathrm{~h}$ at room temperature. The poly(methacrylic acid) was reacted with diazomethane in dry benzene to be transformed to PMMA. The $\bar{M}_{n}$ and $\bar{M}_{w} /$ $\bar{M}_{n}$ (by GPC) of this PMMA were 3300 and 1.06 , respectively. After purification with preparative GPC (Shodex K-2003 column), no residual 1-phenyldibenzosuberyl or hydroxycarbonyl moiety in the PMMA was detected by ${ }^{1} \mathrm{H}$ NMR.

\section{Chromatographic Procedures}

SFC was performed on a JASCO SUPER200 chromatograph equipped with a HewlettPackard 5890 column oven. A $10 \mathrm{~mm}$ i.d. $\times$ $250 \mathrm{~mm}$ column packed with non-bonded silica gel (Develosil 100-5, Nomura Chemical Co., Ltd., particle size $5 \mu \mathrm{m}$ ) was used. Carbon dioxide containing $38 \mathrm{vol} \%$ methanol was employed as a mobile phase, and the fluid pressure was controlled to $20 \mathrm{MPa}$. The chromatographic separation was run by the temperature gradient method. Further details of SFC were described previously. ${ }^{3,4}$

Separation and purification of the $7 \mathrm{mer}$ of 2 were carried out by the HPLC procedure described in a previous paper. ${ }^{18}$

\section{Measurements}

${ }^{1} \mathrm{H}$ NMR spectra of PMMA samples were recorded on a JEOL JNM-GX500 spectrometer in nitrobenzene- $d_{5}$ at $110^{\circ} \mathrm{C}$. Chemical shifts were referred to hexamethyldisiloxane (HMDS) added as an internal standard and given in the HMDS scale. ${ }^{9}$

Molecular mass of the uniform $15 \mathrm{mer}\left(\mathrm{C}_{76^{-}}\right.$ $\left.\mathrm{H}_{124} \mathrm{O}_{30}=1516\right)$ and $18 \mathrm{mer}\left(\mathrm{C}_{91} \mathrm{H}_{148} \mathrm{O}_{36}=\right.$ 1816) of 2 were determined clearly using a JEOL JMS-DX303HF spectrometer operated at the field-desorption mode.

DSC measurements were performed on a Rigaku DSC-8230 instrument under nitrogen flow $\left(15 \mathrm{ml} \mathrm{min}^{-1}\right)$. The temperature response of the calorimeter was calibrated with the melting points of high-purity samples of benzophenone and indium. The DSC curves for the determination of $T_{\mathrm{m}}$ were recorded at a heating rate of $5^{\circ} \mathrm{C} \mathrm{min}^{-1}$. Sample size ranged from 1.94 to $2.02 \mathrm{mg}$. $T_{\mathrm{m}}$ was defined as the intersection of the initial baseline and the sloping portion of the curve ( $c f$., Figure 4).

\section{X-Ray Crystallographic Determination of the Uniform 7 mer of 2}

$\mathrm{X}$-Ray data of the 7 mer of 2 were collected with a Rigaku AFC7R automated four-circle diffractometer with graphite monochromated Mo- $K_{\alpha}$ radiation and a $12 \mathrm{~kW}$ rotating anode generator. The structure was solved by direct methods (MULTAN88). Positions of all non-hydrogen atoms were refined with isotropic thermal parameters. Hydrogen atoms were placed in idealized positions. The final $R$ and $R_{w}$ values were 0.075 and 0.056 , respectively, for the structure refined by the least-squares method using 1000 unique reflections $\left(2 \theta<45^{\circ}\right)$ with $I>3.0 \sigma(I)$.

\section{RESULTS AND DISCUSSION}

\section{Analysis of Configurational Purity of the Iso-} tactic PMMA 2

Figure 1 shows the methyl proton resonances in ${ }^{1} \mathrm{H}$ NMR spectra of the PMMA 1 obtained in our previous work ${ }^{3}$ and of the PMMA 2 derived from poly(PDBSMA). Besides the strong resonance at $1.327 \mathrm{ppm}$ due to the $\mathrm{mmmm}$ pentad of the $\alpha$-methyl groups, there appear small signals arising from the methyl groups in the chain-end triads $(a, b, c, x, y, z$ in eq 1 , and $a, b, c$ in eq 2 ). The assignments of these signals for 1 were made on the basis of two-dimensional NMR experiments. ${ }^{9,19}$ What is evident on comparing the two spectra is the absence of $x-, y$-, and $z-\mathrm{CH}_{3}(m)$ res- 
K. UTE et al.

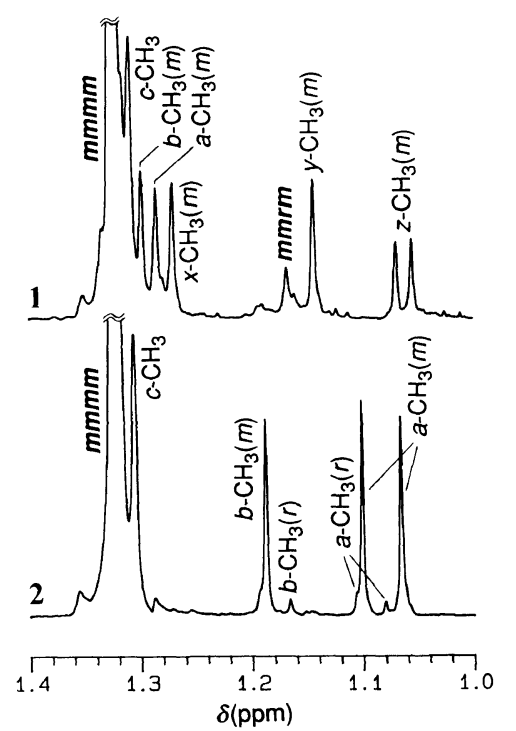

Figure 1. $\alpha-\mathrm{CH}_{3}$ resonances in the ${ }^{1} \mathrm{H}$ NMR spectra of PMMA $1\left(\bar{M}_{n}=2.24 \times 10^{3}\right)$ (a) and PMMA $2\left(\bar{M}_{n}=3.30 \times\right.$ $10^{3}$ ) (b) (nitrobenzene- $d_{5}, 110^{\circ} \mathrm{C}, 500 \mathrm{MHz}$ ).

onances in the spectrum of 2 . This indicates that the PMMA 2 is free from the protonterminated polymer chains which would be formed if the introduction of a methyl terminal to the living poly(PDBSMA) anions were incomplete. While a small signal due to the $m m r m$ pentad appeared at $1.167 \mathrm{ppm}$ in the spectrum of 1 whose isotacticity was $96.1 \%$ in triads, the $\mathrm{mmrm}$ resonance was not observed in the spectrum of $\mathbf{2}$. Therefore, the stereoregularity of the PMMA 2 can be regarded as almost perfectly isotactic.

In the ${ }^{1} \mathrm{H}$ NMR spectrum of 2 (Figure 1), the two methyl groups of the terminal monomeric unit $\left(\alpha-\mathrm{CH}_{3}\right)$ are diastereotopic. The resonances at 1.066 and $1.101 \mathrm{ppm}$ are attributable to these groups. In addition, a pair of small signals are observed at 1.080 and $1.107 \mathrm{ppm}$. The $b-\mathrm{CH}_{3}$ resonance appears at $1.189 \mathrm{ppm}$, also accompanied by a small resonance at $1.166 \mathrm{ppm}$. These observations suggest that a small amount of configurational disorder (an $r$ sequence) should exist in the $b$ $c$ diad (the monomeric units adjacent to the terminal unit). This $r$ sequence is considered to

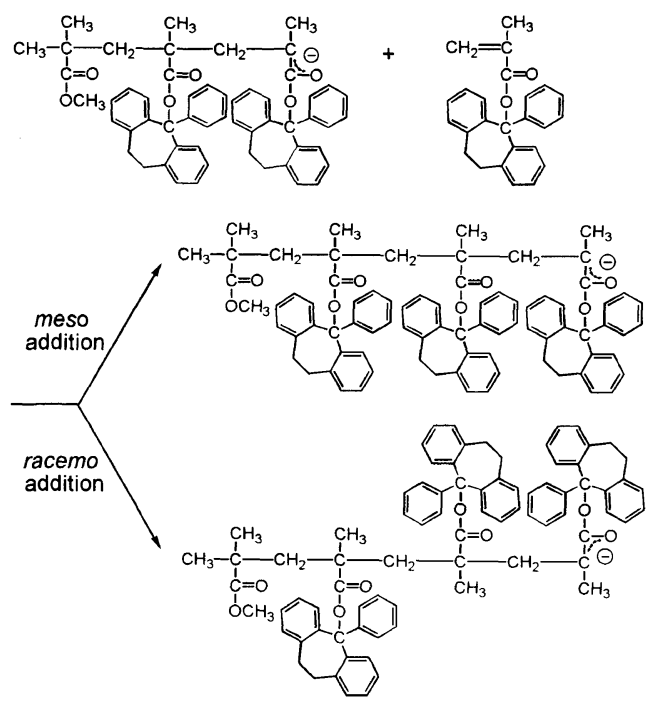

Scheme 2.

be located in the $b-c$ diad at the beginning of chain (the "left" end) but not in the $b-c$ diad at the end of chain (the "right" end) ( $c f$., eq 2). This is because the polymerization of PDBSMA is of extremely high stereospecificity as mentioned above and the methylation of the living polymer anion is non-stereogenic. The $r$ diad would be formed in the early stage of polymerization (in a monomer addition to the trimer anion) where the stereoregulation by the bulky polymer helix may not be very rigorous (Scheme 2). The $m / r$ ratio at the left-end $b-c$ diad was determined to be $89 / 11$ from the relative intensity of the $a-\mathrm{CH}_{3}(m)$ and $a-\mathrm{CH}_{3}(r)$ resonances at 1.066 and $1.080 \mathrm{ppm}$, assuming the $m / r$ ratio at the right-end $b-c$ diad to be 100/0.

Prior to synthesizing the PMMA 2 from poly(PDBSMA), we prepared PMMA 2 from poly(TrMA) by a procedure similar to Scheme 1. The $m / r$ ratio for the left-end $b-c$ diad of this PMMA was 71/29 (Figure 2a) whereas the in-chain tacticity was as high as that of the PMMA derived from poly(PDBSMA). When $t$-butyl $\alpha$-lithioisobutyrate was used as an initiator in the polymerization of TrMA, the $m / r$ ratio for the left-end $b-c$ diad decreased 
to $68 / 32$. For this reason, the PMMA 2 derived from poly(PDBSMA) was employed in the following investigations.

Figure 3a shows an SFC chromatogram of PMMA 2 with an average $D P$ of $33.1\left(\bar{M}_{w} /\right.$ $\left.\bar{M}_{n}=1.06\right)$. The $D P$ for each peak in the

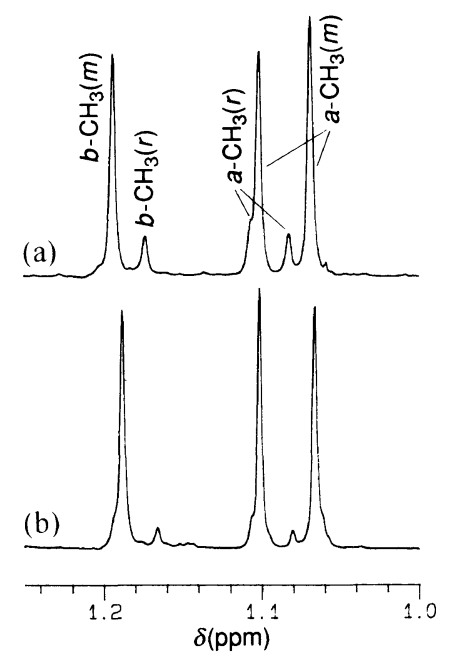

Figure 2. ${ }^{1} \mathrm{H}$ NMR signals due to the methyl groups of the terminal two monomeric units in the PMMAs 2 derived from poly(TrMA) (a) and poly(PDBSMA) (b) (nitrobenzene- $d_{5}, 110^{\circ} \mathrm{C}, 500 \mathrm{MHz}$ ).

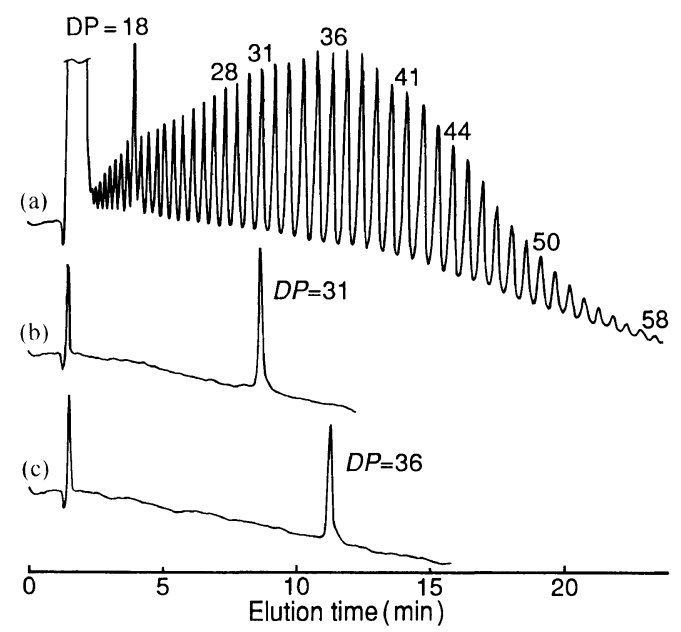

Figure 3. SFC traces of isotactic PMMA $2(D P=33.1$, $\bar{M}_{w} / \bar{M}_{n}=1.06$ ) (a) and of the 31 mer (b) and 36 mer (c) isolated therefrom. An authentic sample of the $18 \mathrm{mer}$ was added to the parent PMMA (a) as an internal standard of DP. chromatogram was determined relative to the peak due to an authentic sample of the $18 \mathrm{mer}$ added to the PMMA. Uniform PMMAs with $D P$ 's from 28 to 44 were obtained by repeated

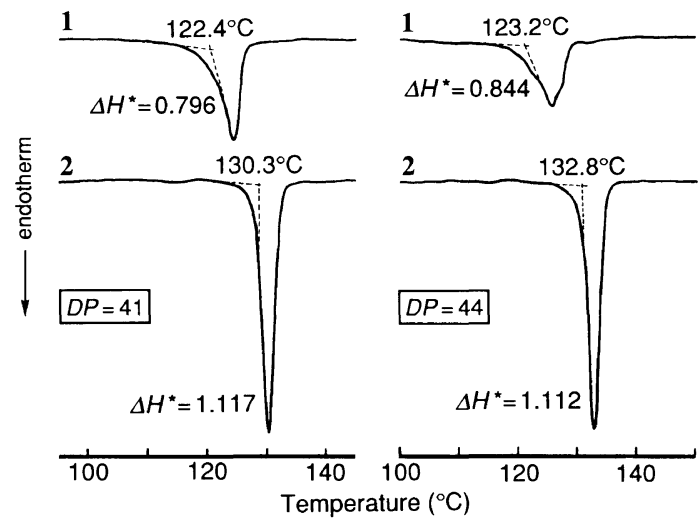

Figure 4. Melting endotherms of the uniform 41 mers and $44 \mathrm{mers}$ of 1 and 2 (heating rate, $5^{\circ} \mathrm{Cmin}^{-1}$ ). $\Delta H^{*}$ values are given in $\mathrm{kcal} \mathrm{mol}^{-1}$.

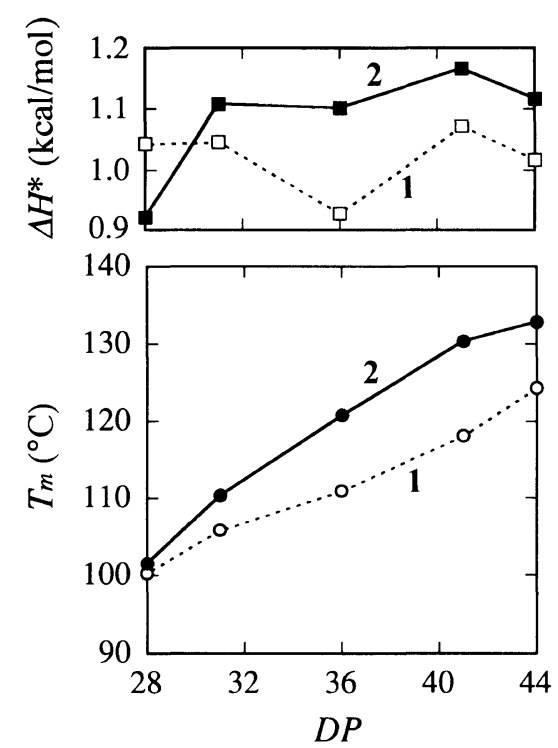

Figure 5. Melting temperature $\left(T_{\mathrm{m}}\right)$ and observed heat of fusion per repeating unit $\left(\Delta H^{*}\right)$ of the uniform PMMA $1(O, \square)$ and uniform PMMA $2(\boldsymbol{O}, \mathbf{\square})$ samples crystallized from methanol solutions as plotted against $D P$. The $T_{m}$ and $\Delta H^{*}$ for PMMA 2 were determined by DSC measurements at a heating rate of $5^{\circ} \mathrm{Cmin}^{-1}$. The data for PMMA 1 were reproduced from a previous paper ${ }^{7}$ with a minor correction regarding a heating rate (evaluated by interpolating the data obtained at 3 and $10^{\circ} \mathrm{Cmin}^{-1}$ to $5^{\circ} \mathrm{C} \min ^{-1}$ ). 
fractionation with the SFC. Re-injecting the $31 \mathrm{mer}$ and $36 \mathrm{mer}$ fractions exhibited a single peak in each chromatogram as shown in Figures $3 b$ and $3 c$.

\section{Difference in Crystallinity between the Uniform PMMAs 1 and 2}

Uniform polymers and oligomers are excellent model compounds for study of the crystallinity of polymers, as can be judged by the interest in the crystallinity of the normal alkanes with chain lengths up to 390 methylene units $\left(\mathrm{C}_{390} \mathrm{H}_{782}=5472.5\right)^{20}$ and that of the oligo(oxyethylene)s with chain lengths up to 45 oxyethylene units $\left(\mathrm{C}_{90} \mathrm{H}_{182} \mathrm{O}_{45}=2020.7\right) .{ }^{21} \mathrm{As}$ described in a previous paper, ${ }^{7}$ uniform PMMA 1 shows crystallinity much higher than that of the non-uniform PMMA 1 with a nearly equivalent $D P$. For instance, the uniform isotactic $41 \mathrm{mer}$ of $\mathrm{I}\left(\mathrm{C}_{209} \mathrm{H}_{338} \mathrm{O}_{82}=4162.9\right)$ crystallized by solvent evaporation had $T_{\mathrm{m}}$ of $122.3^{\circ} \mathrm{C}$ which is $2.9^{\circ} \mathrm{C}$ higher than $T_{\mathrm{m}}$ of its parent PMMA 1 with an average $D P$ of 40.8 $\left(\bar{M}_{w} / \bar{M}_{n}=1.12\right)$ crystallized under the same conditions; the observed heat of fusion per repeating unit $\left(\Delta H^{*}\right)$ was $0.943 \mathrm{kcal} \mathrm{mol}^{-1}$ for the former and $0.416 \mathrm{kcal} \mathrm{mol}^{-1}$ for the latter. It is of our present interest to examine the effect of structural differences between $\mathbf{1}$ and $\mathbf{2}$ on the crystallinity of the uniform polymers.

The samples of uniform 2 with $D P$ of 28 , $31,36,41$, and 44 were dissolved in methanol, respectively $(20 \mathrm{mg} / 20 \mathrm{ml})$, and then crystallized by evaporating the solvent slowly at room temperature to dryness. At the same time, crystallization of the uniform 41 mer and $44 \mathrm{mer}$ of 1 was also carried out in a similar way. Figure 4 illustrates the melting endotherms of the crystalline 41 mers and 44mers of 1 and 2. In each $D P$, uniform 2 had higher $T_{\mathrm{m}}$ and larger $\Delta H^{*}$ than uniform 1 . $^{* 1}$ This tendency can also be seen in Figure 5 where the $T_{\mathrm{m}}$ and $\Delta H^{*}$ of

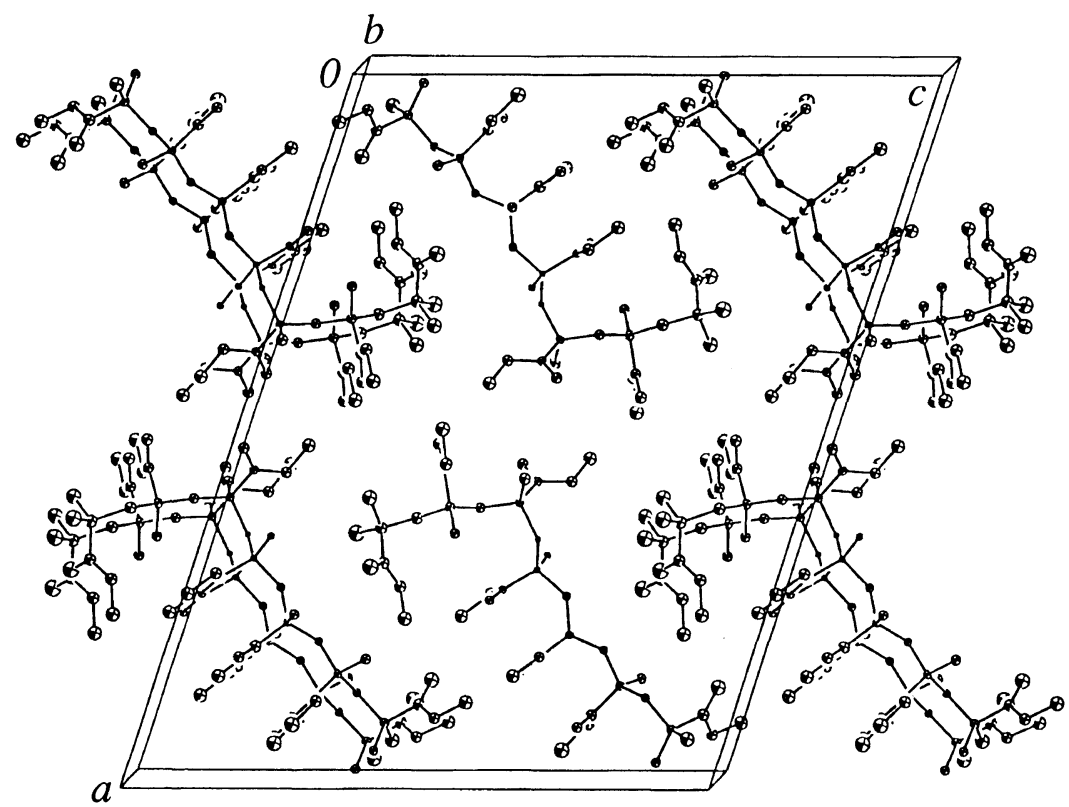

Figure 6. Crystal structure of the isotactic 7 mer of $\operatorname{MMA}(2, n=7)$.

*1 It may be noted that the $\Delta H^{*}$ value for the $41 \mathrm{mer}$ of 1 is somewhat smaller in Figure $4\left(0.796 \mathrm{kcal} \mathrm{mol}^{-1}\right)$ than mentioned above $\left(0.943 \mathrm{kcal} \mathrm{mo}^{-1}\right)$. This suggests lower crystallinity of the $41 \mathrm{mer}$ crystallized in the present work, in spite of the fact that the crystallization was conducted by a procedure similar to the previous work ${ }^{7}$ using the identical stock sample. However, it may safely be said that the 41 mer of 2 has higher tendency to crystallize than the 41 mer of 1 , because the $\Delta H^{*}$ of the former $\left(1.166 \mathrm{kcal} \mathrm{mol}^{-1}\right)$ remains significantly large as compared with the previous value for the latter. 
$\mathbf{1}$ and $\mathbf{2}$ are plotted against $D P$; the data for $\mathbf{1}$ in Figure 5 were taken from a previous paper. ${ }^{7}$ The $T_{\mathrm{m}}$ increased gradually with increasing $D P$, and the $T_{\mathrm{m}}$ of uniform 2 was $1.2-12.2^{\circ} \mathrm{C}$ higher than that of the uniform 1 with the corresponding DP. $\Delta H^{*}$ of the uniform 2 except that of $28 \mathrm{mer}$ ranged from 1.108 to $1.166 \mathrm{kcal} \mathrm{mol}^{-1}$, which was about $10 \%$ larger than $\Delta H^{*}$ of uniform 1. Kusy ${ }^{22}$ has documented that the heat of fusion per repeating unit for perfectly isotactic PMMA with infinite chain length $\left(\Delta H_{\mathrm{u}}\right)$ is expected to be $1.200 \pm$ $0.080 \mathrm{kal} \mathrm{mol}^{-1}$ from the combined linear regression analysis of $\mathrm{X}$-ray diffraction data and DSC. Using this $\Delta H_{\mathrm{u}}$, the degree of crystallinity $\left(w_{\mathrm{c}}\right)$ of the uniform 2 was estimated to be as high as $92-97 \%$ according to the following equation: $w_{\mathrm{c}}=\Delta H^{*} / \Delta H_{\mathrm{u}}$. These results clearly indicate that the crystallinity and $T_{\mathrm{m}}$ of uniform isotactic PMMA should increase significantly by the improvement in in-chain tacticity from 96.1 to nearly $100 \%$ together by the end-group modification to symmetrize the primary structure.

Because of the difficulty of preparing single crystals of uniform 1, X-ray studies have been limited so far to the oligomers up to the 5 mer. ${ }^{23}$ The high crystallinity along with high stereochemical purity of uniform 2 suggests the possibility of growing single crystals of higher oligomers. In fact, thin needle crystals with an $\mathrm{mp}$ of $101.4-101.8^{\circ} \mathrm{C}$ were obtained from a heptane/chloroform solution of the 7 mer of 2 . The 7 mer $\left(\mathrm{C}_{36} \mathrm{H}_{60} \mathrm{O}_{14}=\right.$ 716.8) crystallized in the monoclinic system of space group $\mathrm{P} 2 / c$. The lattice constants are as follows $a=28.819(9) \AA, b=6.215(9) \AA$, $c=22.651(7) \AA, \beta=109.05(2)^{\circ}, V=3834(8) \AA^{3}$, $Z=4, D_{\text {calc }}=1.242 \mathrm{~g} \mathrm{~cm}^{-3}$. Figure 6 shows the crystal structure. Fractional atomic coordinates and isotropic thermal parameters for the 7 mer are given in Table I. The backbone of the 7 mer adopts a planar trans zigzag conformation with a kink in the third monomeric unit, as can be seen in the array of torsional angles from chain-end to chain-end
Table I. Fractional atomic coordinates and isotropic thermal parameters for the isotactic 7 mer of MMA $(2, n=7)$

\begin{tabular}{|c|c|c|c|c|}
\hline Atom & $x$ & $y$ & $z$ & $B$ \\
\hline $\mathrm{O} 1 \mathrm{~A}$ & $0.7119(5)$ & $0.834(3)$ & $0.2841(7)$ & $6.8(5)$ \\
\hline $\mathrm{O} 2 \mathrm{~A}$ & $0.7326(5)$ & 0.559 (2) & $0.3511(6)$ & \\
\hline $\mathrm{ClA}$ & $0.6525(7)$ & 0.379 (4) & $0.251 \quad$ (1) & $6.8(7)$ \\
\hline $\mathrm{C} 2 \mathrm{~A}$ & $0.6510(8)$ & 0.585 (4) & $0.287 \quad$ (1) & \\
\hline $\mathrm{C} 3 \mathrm{~A}$ & $0.6133(7)$ & 0.733 (4) & $0.247 \quad(1)$ & \\
\hline $\mathrm{C} 4 \mathrm{~A}$ & $0.7021(8)$ & $0.673(4)$ & $0.307 \quad$ (1) & \\
\hline $\mathrm{C} 5 \mathrm{~A}$ & $0.7799(7)$ & $0.646(4)$ & $0.3748(9)$ & $5.0(6)$ \\
\hline O1B & $0.5367(5)$ & $0.654(2)$ & $0.3375(6)$ & $3.7(4)$ \\
\hline $\mathrm{O} 2 \mathrm{~B}$ & & & & \\
\hline $\mathrm{C} 1 \mathrm{~B}$ & & & & \\
\hline $\mathrm{C} 2 \mathrm{~B}$ & & & & \\
\hline $\mathrm{C} 3 \mathrm{~B}$ & & & & \\
\hline $\mathrm{C} 4 \mathrm{~B}$ & 0.5728 & & $0.3572(9)$ & \\
\hline $\mathrm{C} 5 \mathrm{~B}$ & $0.5267(8)$ & $1.071(4)$ & 0.328 & $5.4(7)$ \\
\hline $\mathrm{O} 1 \mathrm{C}$ & 0.5565 (4) & $0.338(2)$ & $0.4983(5)$ & \\
\hline $\mathrm{O} 2 \mathrm{C}$ & & & & \\
\hline $\mathrm{C} 1 \mathrm{C}$ & & 0.5 & & \\
\hline $\mathrm{C} 2 \mathrm{C}$ & & 0.62 & & \\
\hline $\mathrm{C} 3 \mathrm{C}$ & & 0.8 & & \\
\hline $\mathrm{C} 4 \mathrm{C}$ & 0.58 & 0.46 & & \\
\hline C5C & 0.5504 (7) & $0.412(3)$ & $0.6086(8)$ & $4.6(6)$ \\
\hline O1D & $0.7513(4)$ & $0.570(2)$ & $0.5107(5)$ & \\
\hline $\mathrm{O} 2 \mathrm{D}$ & 0.7331 & & & \\
\hline C1D & $0.6674(5)$ & 0.652 & $0.5584(7)$ & 0.7 (4) \\
\hline C2D & $0.7052(6)$ & $0.463(3)$ & $0.5773(7)$ & 0.9 (4) \\
\hline C3D & $0.6796(5)$ & 0.263 & $0.5908(7)$ & $1.1(4)$ \\
\hline C4D & 0.7330 (7) & 0.423 & 0.53 & $1.6(5)$ \\
\hline C5D & $0.7629(7)$ & $0.166(4)$ & $0.4793(8)$ & $4.6(6)$ \\
\hline O1E & 0.8469 (4) & $0.348(2)$ & $0.6047(5)$ & \\
\hline $\mathrm{O} 2 \mathrm{E}$ & 0.8334 (4) & & 5) & \\
\hline $\mathrm{C} 1 \mathrm{E}$ & $0.7443(6)$ & $0.536(3)$ & $0.6406(7)$ & $1.7(5)$ \\
\hline $\mathrm{C} 2 \mathrm{E}$ & $0.7961(6)$ & 0.429 (3) & $0.6688(8)$ & $1.6(5)$ \\
\hline $\mathrm{C} 3 \mathrm{E}$ & $0.7918(6)$ & $0.186(3)$ & $0.6709(8)$ & $2.5(5)$ \\
\hline $\mathrm{C} 4 \mathrm{E}$ & $0.8289(7)$ & $0.476(4)$ & 0.629 (1) & $3.6(6)$ \\
\hline C5E & $0.8625(7)$ & 0.758 & 0.5888 (9) & $4.5(6)$ \\
\hline $\mathrm{O} 1 \mathrm{~F}$ & 0.9257 (4) & $0.498(2)$ & 7211 (5) & $2.9(3)$ \\
\hline $\mathrm{O} 2 \mathrm{~F}$ & 0.9122 (5) & $0.162(2)$ & $0.7548(6)$ & $3.5(4)$ \\
\hline $\mathrm{ClF}$ & $0.8201(6)$ & $0.527(3)$ & $0.7344(8)$ & $1.6(4)$ \\
\hline $\mathrm{C} 2 \mathrm{~F}$ & $0.8671(6)$ & $0.441(3)$ & $0.7834(8)$ & $1.9(5)$ \\
\hline $\mathrm{C} 3 \mathrm{~F}$ & $0.8522(6)$ & $0.254(3)$ & $0.8192(8)$ & $2.6(5)$ \\
\hline $\mathrm{C} 4 \mathrm{~F}$ & $0.9053(7)$ & 0.369 (4) & 0.751 & $3.0(6)$ \\
\hline & $0.9470(7)$ & 0.089 (4) & $0.725 \quad(1)$ & $6.1(7)$ \\
\hline $\mathrm{O} 1 \mathrm{G}$ & $0.8724(5)$ & $0.567(2)$ & 00183 & $5.9(4)$ \\
\hline & 0.9311 (4) & $0.321(2)$ & & $3.3(3)$ \\
\hline $\mathrm{ClG}$ & $0.8885(6)$ & $0.624(3)$ & $0.8291(8)$ & $1.6(5)$ \\
\hline $\mathrm{C} 2 \mathrm{G}$ & $0.9312(6)$ & $0.584(3)$ & $0.8917(8)$ & $2.3(5)$ \\
\hline $\mathrm{C} 3 \mathrm{G}$ & 0.9499 (7) & $0.800(4)$ & $0.9186(9)$ & $5.4(6)$ \\
\hline $\mathrm{C} 4 \mathrm{G}$ & 0.9077 (7) & $0.501(4)$ & 0.939 (1) & $3.4(6)$ \\
\hline & $0.9120(7)$ & $0.233(4)$ & $1.0123(9)$ & $4.9(6)$ \\
\hline $\mathrm{C} 1 \mathrm{H}$ & $0.9737(6)$ & $0.452(3)$ & $0.8856(8)$ & $2.3(5)$ \\
\hline
\end{tabular}

a Estimated standard deviations are given in parentheses. 
(from C1A to $\mathrm{C} 1 \mathrm{H}$ in Table I): $175(2)^{\circ}, 168(2)^{\circ}$, $-173(1)^{\circ}, \quad 93(2)^{\circ}, 51(2)^{\circ}, \quad 165(1)^{\circ}, 164(2)^{\circ}$, $173(2)^{\circ}, \quad-169(2)^{\circ}, \quad-159(2)^{\circ}, \quad-169(1)^{\circ}$, $-169(2)^{\circ}$. This conformation lacks symmetry though the primary structure of the $7 \mathrm{mer}$ is symmetrical. A possible crystal structure of isotactic PMMA has been reported to be a double-stranded $10 / 1$ helix with a repeat distance of $20.80-21.12 \AA .{ }^{24-26}$ To prove this double-stranded helical structure by single crystal analysis of uniform PMMA, the chain length of 7 repeating units seems to be insufficient.

Acknowledgments. A part of this work was supported by the Grant-in-Aid for Scientific Research (No. 07555293) from the Ministry of Education, Science, and Culture of Japan.

\section{REFERENCES}

1. K. Hatada, K. Ute, K. Tanaka, Y. Okamoto, and T. Kitayama, Polym. J., 18, 1037 (1986).

2. K. Hatada, K. Ute, T. Nishimura, M. Kashiyama, T. Saito, and M. Takeuchi, Polym. Bull., 23, 157 (1990).

3. K. Ute, N. Miyatake, T. Asada, and K. Hatada, Polym. Bull., 28, 561 (1992).

4. K. Ute, N. Miyatake, Y. Osugi, and K. Hatada, Polym. J., 25, 1153 (1993).

5. K. Hatada, K. Ute, T. Kitayama, T. Nishiura, and N. Miyatake, Macromol. Symp., 85, 325 (1994).

6. K. Hatada, K. Ute, and N. Miyatake, Prog. Polym. Sci., 19, 1067 (1994).
7. K. Ute, N. Miyatake, and K. Hatada, Polymer, 36, 1415 (1995).

8. C. N. McEwen, W. J. Simonsick, Jr., B. S. Larsen, K. Ute, and K. Hatada, J. Am. Soc. Mass Spectrom., in press.

9. K. Hatada, K. Ute, K. Tanaka, M. Imanari, and N. Fujii, Polym. J., 19, 425 (1987).

10. K. Ute, T. Asada, N. Miyatake, and K. Hatada, Makromol. Chem., Macromol. Symp., 67, 147 (1993).

11. H. Yuki, K. Hatada, T. Niinomi, and Y. Kikuchi, Polym. J., 1, 36 (1970).

12. Y. Okamoto, K. Ohta, K. Hatada, and H. Yuki, ACS Symp. Ser., 166, 353 (1981).

13. M. A. Doherty and T. E. Hogen-Esch, Makromol. Chem., 187, 61 (1986).

14. T. Nakano, M. Mori, and Y. Okamoto, Macromolecules, 26, 867 (1993).

15. R. Volpe and T. E. Hogen-Esch, Macromolecules, 23, 4196 (1990).

16. Y. Yuki, Japan Patent 63-41442 (1988).

17. L. Lochmann, M. Rodová, J. Petránek, and D. Lím, J. Polym. Sci., Polym. Chem. Ed., 12, 2295 (1974).

18. K. Ute, T. Nishimura, and K. Hatada, Polym. J., 21, 1027 (1989).

19. K. Hatada, K. Ute, T. Kitayama, K. Tanaka, M. Imanari, and N. Fujii, Polym. J., 21, 447 (1989).

20. G. Ungar, J. Stejny, A. Keller, I. Bidd, and M. C. Whiting, Science, 229, 386 (1985).

21. A. D. Bedells, C. Booth, and K. Viras, Makromol. Chem., 192, 2099 (1991).

22. R. P. Kusy, J. Polym. Sci., Polym. Chem. Ed., 14, 1527 (1976).

23. K. Ute, N. Miyatake, and K. Hatada, J. Macromol. Sci.-Pure Appl. Chem., A29, 599 (1992).

24. H. Kusanagi, H. Tadokoro, and Y. Chatani, Macromolecules, 9, 531 (1976).

25. F. Bosscher, G. ten Brinke, A. Eshuis, and G. Challa, Macromolecules, 15, 1364 (1982).

26. H. Kusanagi, Y. Chatani, and H. Tadokoro, Polymer, 35, 2028 (1994). 